\title{
ESTUDO DA GASTRINEMIA PRÉ E PÓS-OPERATÓRIA EM PACIENTES SUBMETIDOS À GASTROPLASTIA VERTICAL COM BANDA E RECONSTRUÇÃO EM Y DE ROUX POR OBESIDADE MÓRBIDA
}

\author{
THE BEHAVIOUR OF PRE AND POST OPERATIVE GASTRINEMIA IN PATIENTS \\ SUBMITTED TO VERTICAL BANDED GASTROPLASTY WITH ROUX-EM-Y GASTRIC \\ BYPASS FOR MORBID OBESITY
}

\author{
Edmundo Anderi Jr, TCBC-SP1; Felipe Martin Bianco Rossi²; \\ Carla Komon de Souza²; Alcino Lázaro da Silva, ECBC-MG³
}

\begin{abstract}
RESUMO: Objetivo: Avaliar as concentrações pré e pós-operatória da gastrina sérica, hormônio fundamental na produção do ácido clorídrico gástrico, correlacionando-as com as complicações cloridropépticas pós-cirúrgicas, em pacientes submetidos à gastroplastia vertical com banda e reconstrução em Y de Roux (GVBYR). Método: Foram incluídos neste estudo, 20 pacientes com Índice de Massa Corpórea (IMC) superior a $40 \mathrm{Kg} / \mathrm{m}^{2}$ selecionados após rigorosa avaliação psicológica. A dosagem da gastrina foi realizada no pré e no pós-operatório. Neste mesmo período todos os pacientes forma também submetidos a exame endoscópico com biópsia para estudo histopatológico. Resultados: As quantidades de gastrina produzidas antes e após o tratamento cirúrgico não diferiram significativamente $(\mathrm{p}=0,4281)$. Nenhum paciente apresentou alteração endoscópica ou histológica até o $2^{\circ}$ mês de pós-operatório. Conclusão: Após a realização da GVBYR ocorre uma adaptação do tubo digestivo, de modo a manter a sua fisiologia, conduzindo-nos à convicção da segurança dessa técnica no tratamento da obesidade mórbida (Rev. Col. Bras. Cir. 2008; 35(6): 392-396).
\end{abstract}

Descritores: Obesidade mórbida; Cirurgia bariátrica; Gastroplastia; Gastrinas; Anastomose em Y-de-Roux.

\section{INTRODUÇÃO}

Definida como um excesso de tecido adiposo, a obesidade é quantificada pelo Índice de Massa Corpórea (IMC), equação obtida pela divisão do peso em quilogramas pelo quadrado da altura em metros. Cerca de $27 \%$ da população norte-americana é obesa, dentre os quais cinco milhões são classificados como obesos extremos (IMC> $40 \mathrm{Kg} / \mathrm{m}^{2}$ ), o que corresponde a $1 \%$ da população ${ }^{1}$. A obesidade excessiva está intimamente associada à doenças como arteriosclerose, esteatose hepática, dislipidemia, hipertensão arterial, infarto do miocárdio, acidente vascular cerebral, e insuficiências cardiovasculares, além dos distúrbios endócrinos e articulares $^{2}$.

A obesidade mórbida é uma doença refratária ao tratamento clínico ${ }^{3,4}$, sendo que a sua taxa de recidiva chega a $98 \%$. Nesse caso, a única opção para o controle da obesidade a longo prazo, é o tratamento cirúrgico ${ }^{5}$. Diversas técnicas cirúrgicas têm sido utilizadas nas últimas cinco décadas, porém o procedimento considerado padrão-ouro no tratamento da obesidade mórbida é a gastroplastia vertical com ou sem anel de sylastic e reconstrução em Y de Roux (GVBYR), proposta paralelamente por Fobi e por Capella. Esta operação se utiliza do Y de Roux, para exclusão intestinal e reconstrução do trânsito digestivo, encontrando-se na literatura diferentes variações técnicas com relação ao tamanho do componente disabsortivo ${ }^{6}$, apresentando uma perda média do excesso de peso de $75 \%$, embora algumas complicações tenham sido relatadas?.

As complicações relacionadas à secreção cloridropéptica podem ocorrer no primeiro mês após a cirurgia ou tardiamente. No pós-operatório precoce, tais compliações representam a principal causa de sangramento gastrointestinal, podendo apresentar-se como: úlceras marginais, úlceras no estômago excluso, gastrites e sangramentos na linha de grampos. No pós-operatório, a incidência de deiscências na linha de grampos varia de $1 \%$ a $23 \% .^{8-10}$. A incidência de úlceras marginais após o GVBYR é de $3 \%$ a $10 \%^{11,12}$, sendo mais freqüentes na porção jejunal da gastroenterostomia.

A secreção gástrica de acido clorídrico e de pepsinogênio é fundamental na degradação de proteínas em polipeptídeos e aminoácidos, possibilitando suas absorções entéricas. O estimulo à sua produção e liberação é químico e neural, exigindo integridade do sistema vagal e principalmente da secreção de gastrina.

A gastrina é um heptadecapeptídeo produzidos pelas mucosas do antro e do duodeno frente à presença do

1. Chefe do Serviço de Cirurgia de Obesidade da Faculdade de Medicina do ABC.

2. Acadêmico da Faculdade de Medicina do ABC.

3. Professor Titular de Cirurgia da Faculdade de Medicina da UFMG.

Recebido em 30/06/2008

Aceito para publicação em 28/08/2008

Conflito de Interesses: nenhum

Fonte de financiamento: nenhuma

Trabalho realizado no Serviço de Cirurgia Bariátrica da Disciplina de Cirurgia do Aparelho Digestivo da Faculdade de Medicina do ABC. 
alimento (estímulo natural ou fisiológico que alcaliniza a cavidade gástrica). A distensão antral (e em menor proporção, do fórnix) é outro poderoso estímulo à sua liberação. $\mathrm{O}$ estímulo vagal representa o terceiro mecanismo para a síntese e liberação deste hormônio ${ }^{13}$.

A gastroplastia vertical com a banda e anastomose em Y de Roux cria um compartimento gástrico excluso e parcialmente desnervado, cujo controle neural faz-se ascendentemente pelo ramo de Latarjet. Teoricamente, a inexistência de alimento no estômago excluso, impede a sua alcalinização e o suco cloridropéptico produzido (secreção basal) alcança o duodeno e, banhando sua mucosa, induz a produção de secretina, regulador de secreção de gastrina, permanecendo fisiológica a produção da gastrina. Porém, a lei de desnervação de Cannon postula que um órgão parcialmente desnervado torna-se hipersensível à estímulos químicos, como no experimento da "alimentação simulada" em que o estômago excluso responde secretoriamente à deglutição do alimento devido à atuação vagal com secreção de gastrina e ácido clorídrico ${ }^{14}$.

Considerando-se a grande importância da secreção gástrica na ocorrência de complicações pós-operatórias em pacientes submetidos à GVBYR, o presente estudo tem por objetivo avaliar as concentrações pré e pós-operatórias da gastrina sérica, correlacionando-as com as complicações cloridropépticas pós-cirúrgicas, em pacientes submetidos à gastroplastia vertical com banda e reconstrução em Y de Roux, além de estudo endoscópico e histopatológico do coto gástrico.

\section{MÉTODO}

Foram incluídos neste estudo, 20 pacientes com Índice de Massa Corpórea (IMC) superior a $40 \mathrm{~kg} / \mathrm{m}^{2}$. Uma vez indicada a operação, todos os pacientes foram submetidos ao protocolo aprovado pelo Comitê de Ética em Pesquisas da FMABC. Este protocolo consistia na concordância com a indicação pela equipe de endocrinologia e de uma rigorosa avaliação psicológica, que incluía testes projetivos gráficos, visando à identificação de transtornos psicológicos que pudessem se exacerbar e comprometer o pós-operatório, além de estudo e orientação nutricional e exames laboratoriais e complementares (ultrassonografia de abdome total, endoscopia digestiva alta com pesquisa e erradicação do Helicobacter pylori, teste ergométrico, espirometria radiografia simples de tórax e ecocardiograma). Todos os pacientes incluídos neste estudo foram submetidos à GVBYR pelo Serviço de Cirurgia Bariátrica da FMABC.

No pré-operatório dos pacientes em estudo foram colhidos $7 \mathrm{ml}$ de sangue venoso periférico para dosagem por radioimunoensaio de gastrina. No $60^{\circ} \mathrm{PO}$ foi colhida nova amostra para estudo da gastrina sérica e realizada endoscopia digestiva alta e biópsia do coto gástrico para estudo histopatológico.

Para o estudo estatístico utilizou-se o teste " t" Student para amostras pareadas. Consideramos como significativos valores de "p" inferiores a 0,05 .

\section{RESULTADOS}

Em nosso estudo, a dosagem pré-operatória por radioimunoensaio da gastrina revelou valores normais (inferiores a $200 \mathrm{ng} / \mathrm{ml}$ ) nos 20 pacientes. Após dois meses de P.O., nova colheita revelou que em onze pacientes houve aumento destes valores, sendo que destes, apenas cinco tiveram acréscimo de $20 \mathrm{ng} / \mathrm{ml}$ ou mais e nenhum ultrapassou o limite da normalidade ( média de acréscimo de 20ng). Em nove pacientes observou-se decréscimo dos níveis de gastrina, sendo que em apenas uma paciente, esta diminuição foi maior que 20ng/ml ( média de decréscimo de 14,4 ng/ml).

Como " $t$ " calculado não diferiu significativamente de zero $(-0,814)$ as quantidades de gastrina produzidas, antes e após o ato operatório, não diferiram pois a média de diferenças não pode ser considerada significativamente diferente de zero. O valor de " $p$ " obtido foi de 0,4257 ( $p>0,05)$.

Como a média pode adquirir o valor zero, pois ele está incluído no intervalo de confiança de 95\%, chega-se a conclusão de que as quantidades produzidas de gastrina não diferem significativamente em relação à cirurgia.

Nenhum paciente apresentou alterações endoscópicas e histológicas detectáveis no $2^{\circ}$ mês de pós-operatório, em comparação ao período pré-operatório. A tabela 1 mostra as gastrinemias obtidas de cada paciente estudado, bem como suas idades, IMC pré-operatório e resultados endoscópicos e histológicos.

A figura 1 compara graficamente a média das gastrinemias pré e pós-operatórias:

\section{DISCUSSÃO}

A obesidade excessiva é hoje conhecida como condição grave e que se inclui na área cirúrgica porque implica em piora da qualidade de vida, pela alta morbidez associada, redução da expectativa de vida e altíssima probabilidade de fracasso dos tratamentos conservadores ${ }^{15}$.

A cirurgia de Fobi-Capella reduz drasticamente a capacidade do estômago de receber alimento e provoca uma chegada ao jejuno proximal sem a ação enzimática normal, além de aumentar a sensação de saciedade precoce ${ }^{16}$, resultando , em média, em perdas ponderais permanentes, da ordem de $40 \%$ do peso inicial após um ano ${ }^{17}$, e $35 \%$ após seis $\operatorname{anos}^{18}$.

Esta operação, porém, apresenta complicações , muitas delas relacionadas à secreção cloridropéptica. Esta é altamente complexa, envolvendo mecanismos nervosos, realizados por fibras parassimpáticas do nervo vago e pelo plexo mioentérico local e mecanismos humorais representados pela gastrina.

Impulsos nervosos originando-se nos núcleos motores dorsais do vago atingem o plexo mioentéricos e destes, as células oxínticas via acetilcolina. A histamina produzida pelos mastócitos e a gastrina secretadas pelas células $\mathrm{G}$ do antro também estimulam as células parietais,sendo chamados de primeiros mensageiros. Cada um destes reguladores químicos fixa-se a um receptor especifico na parede do pólo basal da célula, iniciando a formação de um segundo mensageiro no interior celular ${ }^{19}$. 
Tabela 1 - Resultados das gastrinemias e achados endoscópicos e histológicos ( $1^{\circ}$ ao $20^{\circ}$ paciente).

\begin{tabular}{|c|c|c|c|c|c|c|c|}
\hline \multirow{2}{*}{\multicolumn{2}{|c|}{ Paciente Idade }} & \multirow[t]{2}{*}{ IMC } & \multicolumn{2}{|c|}{ Gastrina } & \multirow{2}{*}{$\begin{array}{c}\text { Endoscopia } \\
\text { pré-operatoria }\end{array}$} & \multirow{2}{*}{$\begin{array}{c}\text { Endoscopia } \\
\text { pós-operatoria }\end{array}$} & \multirow{2}{*}{$\begin{array}{c}\text { Histologia } \\
\text { pós-operatória }\end{array}$} \\
\hline & & & Inicial (ng) & P.O. (ng) & & & \\
\hline 1 & 34 & 43,7 & 108 & 64 & GELA Hp neg & Normal Hp. Neg & Gastrite crônica inativa \\
\hline 2 & 31 & 49 & 64 & 105 & GELA Hp neg & Normal Hp neg & Gastrite crônica inativa \\
\hline 3 & 51 & 62 & 90 & 70 & HH GEMA Hp neg & Normal Hp neg & Gastrite crônica inativa \\
\hline 4 & 43 & 45,6 & 65 & 93 & GELA Hp neg & Normal Hp neg & Gastrite crônica inativa \\
\hline 5 & 25 & 55 & 105 & 95 & Normal & Normal Hp neg & Gastrite crônica inativa \\
\hline 6 & 37 & 45 & 79 & 90 & GELA Hp neg & Normal Hp neg & Gastrite crônica inativa \\
\hline 7 & 34 & 49 & 83 & 74 & Normal & Normal Hp neg & Gastrite crônica inativa \\
\hline 8 & 39 & 62 & 66 & 78 & HH GELA Hp. neg & Normal Hp neg & Gastrite crônica inativa \\
\hline 9 & 36 & 53 & 76 & 65 & GELA Hp neg & Normal Hp neg & Gastrite crônica inativa \\
\hline 10 & 36 & 51,5 & 67 & 70 & GELA Hp neg & Normal Hp neg & Gastrite crônica inativa \\
\hline 11 & 32 & 58 & 84 & 90 & GELA Hp neg & Normal Hp neg & Gastrite crônica inativa \\
\hline 12 & 45 & 52,2 & 109 & 103 & HH GELA Hp. neg & Normal Hp neg & Gastrite crônica inativa \\
\hline 13 & 32 & 44,8 & 105 & 114 & Normal & Normal Hp neg & Gastrite crônica inativa \\
\hline 14 & 29 & 48,7 & 60 & 59 & Esofagite & Normal Hp neg & Gastrite crônica inativa \\
\hline 15 & 29 & 45 & 65 & 102 & GELA Hp neg & Normal Hp neg & Gastrite crônica inativa \\
\hline 16 & 27 & 42,9 & 53 & 95 & GELA Hp neg & Normal Hp neg & Gastrite crônica inativa \\
\hline 17 & 29 & 53 & 73 & 115 & Esofagite ; HH & Normal Hp neg & Gastrite crônica inativa \\
\hline 18 & 17 & 53,7 & 96 & 78 & GELA Hp neg & Normal Hp neg & Gastrite crônica inativa \\
\hline 19 & 53 & 48,4 & 92 & 65 & GELA Hp neg & Normal Hp neg & Gastrite crônica inativa \\
\hline 20 & 41 & 55 & 69 & 72 & GELA Hp neg & Normal Hp neg & Gastrite crônica inativa \\
\hline
\end{tabular}

$H H=$ Hérnia do hiato por deslizamento $\quad$ GEMA = gastrite enantematosa antral moderada

$H p=$ Helicobacter pylori $\quad$ Neg = negativo

GELA = gastrite enantematosa antral leve $\quad$ Pos $=$ positivo

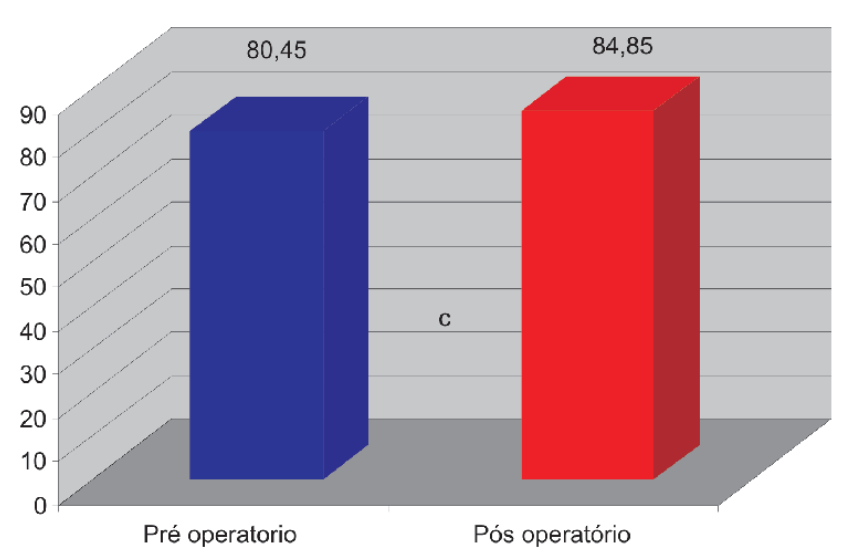

Figura 1 - Gráfico Demonstrativo das médias das gastrinas séricas pré e pós-operatórias.

Pequenas quantidades de ácido são constantemente secretadas, mesmo em vigência de jejum (secreção basal). $\mathrm{O}$ gosto, o odor, a lembrança, a mastigação e a deglutição estimulam uma maior produção oxíntica, etapa esta conhecida como fase cefálica da secreção cloridropéptica, iniciando reflexos vagais que liberam acetilcolina de suas terminações.

Até o momento, nenhum estudo analisou as alterações da secreção da gastrina no tratamento cirúrgico da obesidade. Porém, McLean et al ${ }^{20}$, em 1997, estudaram o comportamento da secreção ácida em pacientes submetidos a cirurgia de gastroplastia sem transecção gástrica com reconstrução em Y de Roux. Este estudo demonstrou que os pacientes que desen- volveram úlcera estomal, haviam desenvolvido anteriormente ruptura na linha de grampos separando o coto gástrico do estômago afastado do trânsito. Esses pacientes apresentavam também, um aumento na acidez do coto gástrico, com queda do $\mathrm{pH}$ para menos de dois por um período de tempo maior que o grupo controle de pacientes sem complicações. Também os pacientes que desenvolveram fístula apresentavam maior secreção ácida e queda do $\mathrm{pH}$ em relação ao grupo controle, embora de forma menos acentuada que os pacientes que desenvolveram úlcera. Após a correção da linha de grampos, a secreção ácida e o pH do coto retornaram a níveis encontrados em pacientes controle. Os resultados do estudo parecem demonstrar que a hipersecreção ácida foi produzida somente no estômago fora do trânsito intestinal, enquanto que o coto gástrico produziu uma quantidade insignificante. Possivelmente, em alguns pacientes, o estômago excluso tornou-se hipersensível à atuação vagal, respondendo com maior secreção de gastrina e ácido clorídrico (Lei da desnervação de Cannon).

O estudo realizado por Lukasiewicz et al $^{21}$ quantificou a secreção de gastrina anteriormente e posteriormente à gastroenteroanastomose em Y de Roux para o tratamento de úlceras pépticas e descobriu que no pós-cirúrgico, a secreção de gastrina diminuiu, devido a resseção do antro gástrico e exclusão do duodeno do trânsito intestinal. De acordo com o estudo, a secreção ácida basal e pós-estímulo de pentagastrina também diminuiu. Esta redução ácida pode ser responsável pela ínfima recorrência de úlceras após procedimentos de ressecção cirúrgica quando comparados à somente desnervação cirúrgica. 
Em nosso estudo, a dosagem pré e pós-operatória da gastrinemia, por radioimunoensaio, revelou valores normais (inferiores a 200ng/ml) nos 20 pacientes e sem diferenças estatísticas significantes.

As endoscopias digestivas altas realizadas no préoperatório revelaram 17 casos de gastrite endoscópica, três casos de hérnia por deslizamento, dois casos de esofagite e presença do Helicobacter pylori em um caso, sendo erradicado com uma associação de omeprazol 40ml/dia, amoxicilina $2,0 \mathrm{~g} / \mathrm{dia}$ e azitromicina $500 \mathrm{mg} / \mathrm{dia}$. O exame endoscópico pós-operatório não foi capaz de identificar nenhuma alteração macroscópica do coto gástrico, referindo em todos os 20 pacientes a diminuição acentuada do reservatório gástrico, a perviedade e integridade da anastomose gastrojejunal e a identificação da área correspondente ao anel de "sylastic", colocado $2 \mathrm{~cm}$ proximalmente à anastomose.

O estudo histológico das biopsias revelou uniformidade entre os espécimes do mesmo paciente, com manutenção do padrão de gastrite crônica encontrada no pré-operatório, porém inativa, enquanto que os pacientes previamente sem alteração endoscópica ou microscópica pré-operatória, permaneceram com histologia da mucosa do coto normal. Não obtivemos nenhuma complicação pós-operatória que pudesse se relacionar a um aumento da secreção cloridropéptica.

Temia-se que a confecção de uma porção gástrica exclusa do recebimento alimentar, porém parcialmente inervada pelo vago, criasse uma situação ulcerogênica, como no experimento de "REFEIÇÃO SIMULADA" em que os estímulos visuais, olfativos, gustativos e da deglutição, via nervo vago, estimulariam a produção ácida, via gastrina. A não distensão deste segmento gástrico e a não neutralização desse ácido produzido devido a inexistência de alimento neste setor, de- vem funcionar como retroalimentação negativa, levando à diminuição da síntese de gastrina.

Outra explicação plausível para a não ocorrência de oscilações significativas, em nove dos 20 casos deste estudo, até decréscimo dos níveis séricos da gastrina, seria que a presença de ácido clorídrico secretado pelas células oxínticas do estômago excluso, não seria neutralizada pelo $\mathrm{pH}$ alcalino dos alimentos, posto que não atingem este segmento, alcançando o duodeno,estimularia sua mucosa a produzir secretina, que inibiria a produção de gastrina.

A impossibilidade de um estudo a longo prazo de estômago excluso levanta receio quanto o estado da mucosa sem contato com os alimentos, mas principalmente, do comportamento secretório desta mucosa.

Ainda no terreno das especulações, faz-se mister também, postular que o estômago excluso estaria parcialmente denervado, particularmente no fórnix e corpo, pois o grampeamento e secção do mesmo interromperia o trajeto dos nervos vagos direito e esquerdo e ramo posterior estando intacto apenas o ramo de Latarjet, inervando a região antropilórica apenas.

Assim sendo, a fase cefálica da secreção cloridropéptica apenas agiria via gastrina, estando interrompido o estimulo direto dos nervos vagos às células oxínticas, o que justificaria um equilíbrio entre a produção de gastrina e a não produção excessiva de ácido clorídrico, impedindo uma agressão, pelo menos precoce, cloridropéptica a esta mucosa exclusa.

A analise da gastrinemia pré-operatória e no $60^{\circ} \mathrm{PO}$ não revelou modificação estatisticamente significativa, refletindo uma adaptabilidade fisiológica no pós-operatório, conduzindo-nos à convicção da segurança das Gastroplastias Verticais com Banda e Reconstrução Gastrointestinal em Y de Roux no tratamento da obesidade extrema.

\begin{abstract}
Background: This present study shows the preoperative and postoperative serum gastric, a fundamental hormone in the production of gastric chloridric acid, correlating these findings with postoperative complications, in patients submitted to GVBYR. Methods: We selected 20 patients with body mass index (BMI) over $40 \mathrm{Kg} / \mathrm{m}^{2}$ after a rigorous psychological evaluation. Serum gatrin was measured in the preoperative and postoperative periods. These patients were also submitted to upper gastrointestinal endoscopy with biopsy for histological analysis. Results: There was no statistically significant difference between preoperative and postoperative serum gastrin $(p=0.4281)$. Conclusion: Our results show that GVBYR leads to a digestive tract adaptation after surgery, in order to maintain its physiology, suggesting that this procedure is safe for the treatment of morbid obesity. Key-words: morbid obesity*, gastric bypass*, gastrin*.
\end{abstract}

Key words: Obesity, morbid; Bariatric surgery; Gastroplasty; Gastrins; Anastomosis, Roux-en-Y.

\section{REFERÊNCIAS}

1. National Center for Health Statistics. Prevalence of overweight and obesity among adults: United States 1999. Disponível em: URL em http.www.cdc.govnchs/products/pubd/hestats/obese/ obse99.htm. Acessado em junho 20, 2002.

2. Griffen WO Jr. Bariatric surgery in the 1900s. Adv Surg. 1992; 25:99-117.
3. Martin LF, Hunter SM, Lauve RM, O’Leary JP. Severe obesity: expensive to society, frustrating to treat, but important to confront. South Med J. 1995; 88(9):895-902.

4. Methods of voluntary weight loss and control. NIH Technology Assessment Conference Panel. Ann Intern Med. 1992; 116(11):942-9.

5. Fobi MA. Operations that are Questionable for Control of Obesity. Obes Surg 1993; 3(2):197-200. 
6. Buchwald HA. A bariatric surgery algorithm. Obes Surg. 2002; 12(6):733-46; discussion 747-50.

7. Fobi MAL, Lee H, Holness R, Cabinda DG. Gastric bypass operation for obesity. World J Surg. 1998; 22(9):925-35.

8. MacLean LD, Rhode BM, Sampalis J, Forse RA. Results of the surgical treatment of obesity. Am J Surg. 1993; 165(1):155-60; discussion 160-2.

9. Cucchi SG, Pories WJ, MacDonald EK, Morgan EJ. Gastrogastric fistulas. A complication of divided gastric bypass surgery. Ann Surg. 1995;221(4):387-91.

10. Schauer PR, Irkramuddin S, Gourash W, Ramanathan R, Luketich J. Outcomes after laparoscopic Roux-en-Y gastric bypass for morbid obesity. Ann Surg. 2000; 232(4):515-29.

11. Brolin RE. Complications of surgery for severe obesity. Gen Surg. 2000; 17:55-61.

12. Barroso FL, Alonso AS, Leite MA Complicações cirúrgicas intraoperatórias e do pós-operatório recente. In: Garrido Jr AB, Ferraz EM, Barroso FL, Marchesini JB, Szego T. Cirurgia da obesidade. Sociedade Brasileira de Cirurgia Bariátrica. São Paulo: Atheneu; 2002. p. 215-25.

13. Rehefeld JF, Stadil F, Vikelsoe J. Imunoreactive gastrin components in human serum. Gut. 1974; 15(2):102-11.

14. Anderi Jr E. Estudo dos aspectos histológicos da mucosa do coto gástrico e do comportamento da gastrinemia de pacientes com obesidade mórbida submetidos à gastroplastia vertical com banda e reconstrução em Y de Roux [dissertação]. Thesis: pós doutorado em cirurgia;2001.

15. Garrido Jr AB. Situações especiais: tratamento da obesidade mórbida. In: Halpern A. Obesidade. São Paulo: Lemos Editorial; 1998. p. 331-40.

16. Capella RF, Capella J, Mandec H, Nath P. An assessment of vertical banded gastroplasty-Roux-en-Y gastric bypass for the treatment of morbid obesity. Am J Surg. 2002; 183(2):117-23.
17. Garrido Jr AB. Cirurgia em obesos mórbidos - experiência pessoal. Arq Bras Endocrinol Metab. 2000; 44(1):106-13.

18. Fobi MA, Lee H, Igwe D Jr, Stanczyk M, Tambi JN. Prospective comparative evaluation of staple versus transected silastic ring gastric bypass: 6-years follow-up. Obes Surg. 2001; 11(1):1824.

19. Kelly KA, Dozois RR. Secreção e motilidade gástrica na úlcera duodenal. Clin Cir AM Norte. 1976; 1267-76.

20. MacLean LD, Rhode BM. Surgical treatment of obesity: metabolic implications. In: Griffen WO, Printer KJ, editors. Surgical management of morbity obesity. New York: Marcel Dekker; 1987. p. 205-23.

21. Lukasiewicz S, Jonderko K. Partial gastric resection for peptic ulcer comparison of the effect of variant reconstructive procedures on gastric emptying, gastric acid secretion and gastrin release in the early post operative period I. Roux-en-Y and Billroth-II gastroenteroanastomosis. East African Med J. 1994; 71(7):407-13.

Como citar este artigo:

Anderi Jr E, Rossi FM, Souza CK, Silva AL. Estudo da gastrinemia pré e pós-operatória em pacientes submetidos à gastroplastia vertical com banda e reconstrução em Y de Roux por obesidade mórbida. Rev Col Bras Cir. [periódico na Internet] 2008; 35(5). Disponível em URL: http://www.scielo.br/rcbc

Endereço para correspondência:

Edmundo Anderi Jr.

Rua Dom André Arco Verde no 163

Vila Nhocuné

03562-030 - São Paulo - SP

Email: e.anderi@terra.com.br 